\title{
Openings Effect on the Performance of Reinforced Concrete Beams Loaded in Bending and Shear
}

\author{
Fouad El Ame \\ Civil Engineering Department \\ Pan African University \\ Institute for Basic Sciences Technology \\ and Innovation, Nairobi, Kenya \\ elame50@gmail.com
}

\author{
John N. Mwero \\ Department of Civil and Construction \\ Engineering \\ University of Nairobi \\ Nairobi, Kenya \\ mwero@uonbi.ac.ke
}

\author{
Charles K. Kabubo \\ Department of Civil and Construction \\ Engineering \\ Jomo Kenyatta University of Agriculture \\ and Technology, Nairobi, Kenya \\ kabcha2001@gmail.com
}

\begin{abstract}
Transverse openings are often provided to reinforced concrete beams to accommodate utility ducts and pipes. This technique is usually adopted to avoid the creation of dead space in structures caused by extended dropped ceilings and leads to significant cost saving. On the other hand, the provision of openings through a beam creates a reduction in its strength and affects serviceability. In this study, ten reinforced concrete beams were cast using $\mathbf{C 3 0}$ concrete. Material characterization and engineering properties tests were carried out to ensure compliance with the requirements provided by the codes of practice. The effect of vertical positioning and size of openings was investigated through subjecting the beams to a four-point bending test after 28 days of curing. Maximum load capacity, first cracking load, and deflections at mid-span were recorded and crack pattern and failure mode were evaluated. Test data showed that openings of depth greater than $0.4 d$ significantly affect the beams' strength and lead to earlier cracking, while the failure mode remains essentially the same, a diagonal tension crack through the opening except for opening of $0.5 \mathrm{~d}$ size where the failure occurred by a sudden formation of two independent shear cracks above and below the opening. When holes were located above the centroid of the section, the beams exhibited a lesser deflection characterized by the absence of plastic deformation. Furthermore, a significant reduction in strength was recorded compared to cases where the positioning of openings was in tension chords. This was validated using equations from the ACI code of reinforced concrete design.
\end{abstract}

Keywords-circular openings; RC beams; opening size; vertical location; four-point bending test; strength; serviceability

\section{INTRODUCTION}

In practice, the accommodation of services like telephony, water supply, air conditioning, electricity, and sewage requires the provision of a network of ducts and pipes. Most frequently, pipes and tubes are positioned underneath the soffit. The aesthetic implications involve using a suspended ceiling for covering, which creates extra dead spaces in each floor [1]. The provision of openings in beams is a practical solution to avoid extended dropped ceilings, which leads to an economical design and significant cost savings, especially in multistory buildings. The presence of openings produces changes in the behavior of the beams. Openings might be of circular, rectangular, or undefined shape, while in most cases they are placed near the supports where shear stresses are high. Research on perforated beams has started early in the 1960s while trying to comprehend the theory of beams with openings considering various involved parameters. An opening of a circular shape is large when its diameter is greater than $40 \%$ of the beam's effective depth (d), while the square opening is considered large if the height exceeds $0.25 \mathrm{~d}[2,3]$. Authors in [4] tested 27 reinforced concrete beams with openings of different shape, size, and horizontal location and reported that placing holes in flexure zone has lesser impact on the beam performance compared to when the holes are placed in the shear zone. Additionally, circular openings caused the least reduction in ultimate load compared to the other shapes. The regions around the opening experience stress concentration at the corners and possibly transverse cracks. Moreover, the stiffness of the beam can be reduced, which leads to an excessive deflection against the service load and also affects the internal moment and forces distribution throughout the beam [5-7]. According to authors in [3], openings in beams are a source of potential weakness. Failure traverses the openings except the case in which the opening is too close to the support. Authors in [8], after an experimental program on perforated beams, reported that the openings make the beams fail prematurely by an unexpected propagation of an inclined crack in compression chord. Many experimental and analytical studies have been carried out on the effect of openings on beams considering various variables. This research focuses on varying the vertical position of the openings in order to understand the influence of the reduction in the concrete area at compressive and tension chords. The opening size is also a researched parameter.

\section{MATERIALS AND METHODS}

\section{A. Material Characterization}

\section{1) Fine Aggregates}

River sand was obtained locally from Nairobi, Kenya. In this study, gravel was checked for conforming the requirements of British Standard [9], carried out tests were: sieve analysis, specific gravity, water absorption, moisture content, bulk density, and voids content. The test results are presented in Table I and Figure 1. 
TABLE I. CHARACTERIZATION OF FINE AGGREGATES

\begin{tabular}{|c|c|c|}
\hline Test & Test method & Result \\
\hline Specific gravity & BS812: part 2 & 2.41 \\
\hline Water absorption & BS812: part 2 & $2.951 \%$ \\
\hline Moisture content & BS812: part 109 & $0.13 \%$ \\
\hline Bulk density & BS EN 1097-3 & $1680.1 \mathrm{~kg} / \mathrm{m}^{3}$ \\
\hline Voids calculation & BS EN 1097-3 & $35.72 \%$ \\
\hline
\end{tabular}

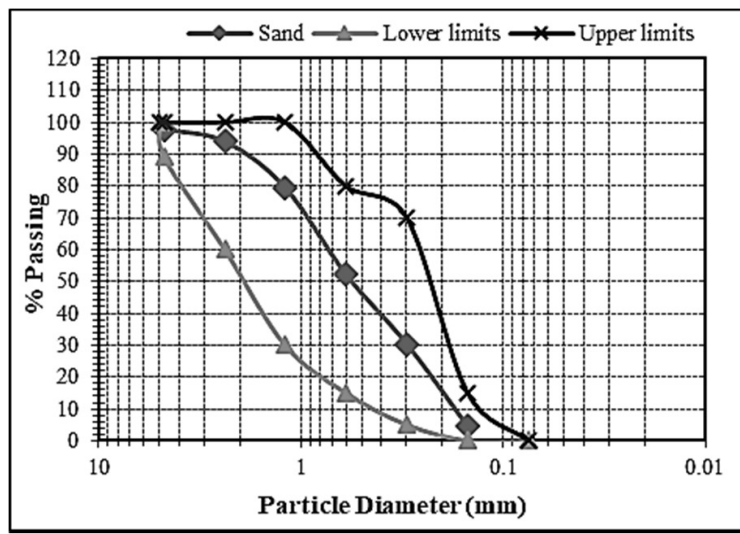

Fig. 1. Fine aggregates particle size distribution

\section{2) Coarse Aggregates}

The gravel was obtained locally from Nairobi, Kenya and was checked for conforming the requirements of [9]. Tests carried out were: sieve analysis, specific gravity, water absorption, moisture content, bulk density, and voids content. The test findings are shown in Table II and Figure 2.

TABLE II. CHARACTERIZATION OF COARSE AGGREGATES

\begin{tabular}{|c|c|c|}
\hline Test & Test method & Result \\
\hline Specific gravity & BS812: part 2 & 2.86 \\
\hline Water absorption & BS812: part 2 & $3.88 \%$ \\
\hline Moisture content & BS812: part 109 & $0.14 \%$ \\
\hline Bulk density & BS EN 1097-3 & $1508.5 \mathrm{~kg} / \mathrm{m}^{3}$ \\
\hline Voids calculation & BS EN 1097-3 & $42.2 \%$ \\
\hline
\end{tabular}

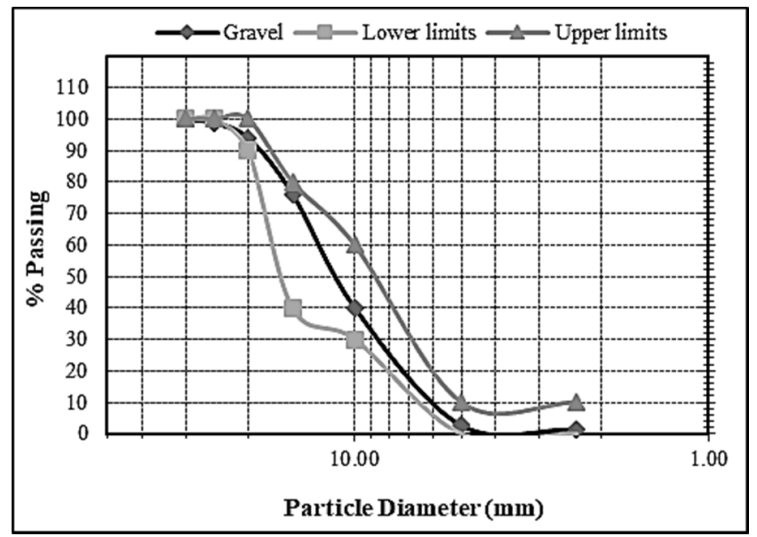

Fig. 2. Coarse aggregates particle size distribution

Particle size distribution, specific gravity on a saturated and surface dried basis, bulk density, and void content for both aggregates fall within the recommended intervals. Therefore the aggregates are suitable for use in construction, hence, in this study.

\section{3) Cement}

The used cement is Portland cement 42.5 , which is highly recommended for structural carrying elements according to BS EN 197-1:2000 [10].

\section{4) Steel}

High tensile steel bars conforming to ASTM-15-65 [11] were adopted for this project. Longitudinal reinforcement was of type T12 with a measured yield stress of 538MPa. Stirrups were type T6 with average yield stress equal to $405 \mathrm{MPa}$.

\section{B. Mix Proportion and Engineering Properties}

The mix design used in the current study was prepared as described in [12] for a target strength of 30MPa. Slump test was carried out as shown in [13] to check the workability in the mix. Mean compressive strength for 7, 14, and 28 days test was conducted on cubes as described in [11] to observe the strength development while tensile strength was also measured. Modulus of elasticity was determined based on the uniaxial stress-strain curve obtained from a standard test cylinder.

TABLE III. ENGINEERING PROPERTIES

\begin{tabular}{|c|c|}
\hline Property & Result \\
\hline Slump & $72 \mathrm{~mm}$ \\
\hline Compressive strength at 28 day & $30.25 \mathrm{MPa}$ \\
\hline Tensile strength at 28 day & $2.8 \mathrm{MPa}$ \\
\hline Modulus of elasticity & $25,125 \mathrm{MPa}$ \\
\hline
\end{tabular}

\section{Specimen}

The specimen design was done as demanded in [14]. Loading assumptions were taken in order to make the case study near to the reality. The simply supported beam had $2 \mathrm{~m}$ span, $150 \mathrm{~mm}$ width, and $200 \mathrm{~mm}$ depth. Concrete strength was $30 \mathrm{MPa}$. The main bars were $\mathrm{T} 12$, while the shear reinforcements used were T6 with a strength of $538 \mathrm{~N} / \mathrm{mm}^{2}$ and $405 \mathrm{~N} / \mathrm{mm}^{2}$ respectively (Figure 3 ).

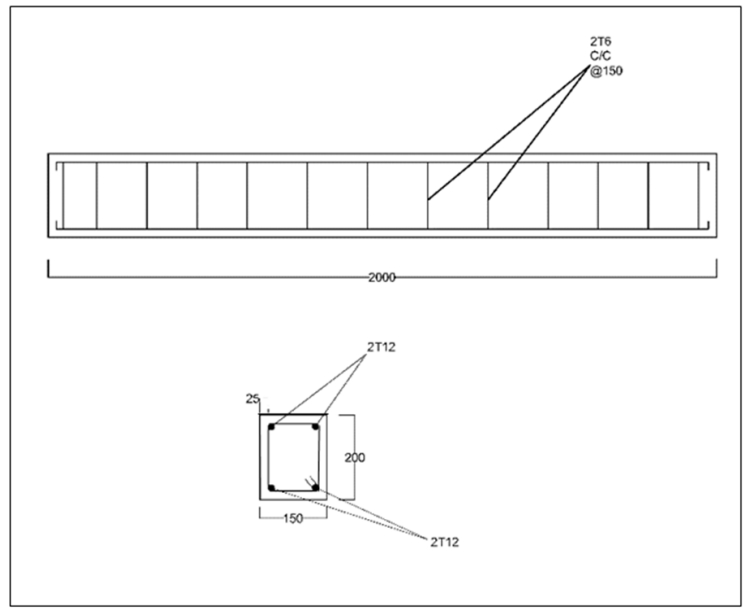

Fig. 3. Beam details

\section{Test Procedure}

This research considered two variables: the size and the vertical position of the openings. The three proposed locations 
were $0.5,0.55$, and 0.6 times the effective depth of the beam while the horizontal location was kept constant at $300 \mathrm{~mm}$ from the supports. The choice of these vertical locations is supported by the question on how the reduction in concrete area within the different chords of the section will affect the serviceability and strength in beams. The proposed opening diameters were $0.3,0.4$, and 0.5 times the effective depth $\mathrm{d}$. Test samples were allocated with codes for simplification. Vertical locations $0.5 \mathrm{~d}$, $0.55 \mathrm{~d}$, and $0.6 \mathrm{~d}$ are respectively denoted as $\mathrm{V} 1, \mathrm{~V} 2$, and $\mathrm{V} 3$. While openings size was coded using the equivalent diameter in $\mathrm{mm}$. 50, 65, 80 are respectively indicating $0.3 \mathrm{~d}, 0.4 \mathrm{~d}$, and $0.5 \mathrm{~d}$. Beams are divided into three sets according to the vertical location. The control beam is represented as $\mathrm{CB}$.

TABLE IV. BEAMS' CODES

\begin{tabular}{|c|c|}
\hline Set & Code \\
\hline Control beam & CB \\
\hline \multirow{3}{*}{1 st set } & PBV1-50 \\
\cline { 2 - 2 } & PBV1-65 \\
\cline { 2 - 2 } & PBV1-80 \\
\hline \multirow{3}{*}{2 nd set } & PBV2-50 \\
\cline { 2 - 2 } & PBV2-65 \\
\cline { 2 - 2 } 3rd set & PBV2-80 \\
\hline & PBV3-50 \\
\cline { 2 - 2 } & PBV3-65 \\
\cline { 2 - 2 } & PBV3-80 \\
\hline
\end{tabular}

All the samples were subjected to a four-point bending test. Each beam was loaded by two symmetrical concentrated loads applied approximately at the span's thirds. This type of test is adopted in order to have a beam type II behavior, which ensures that the span to depth ratio $(\mathrm{s} / \mathrm{d})$ is controlled to fall between 2 and 5, making the beam exposed to flexure and shear at the same time [15]. A hydraulic jack of $400 \mathrm{kN}$ capacity was used to apply the load at the beam tip. A load cell of $200 \mathrm{kN}$ capacity was used to measure the applied load accurately. The gradually increasing load was applied until the failure of the beam. A linear variable differential transducer (LVDT) was used to measure the deformation at the beam midspan. A photo of the monotonic loading test set-up is shown in Figure 4.

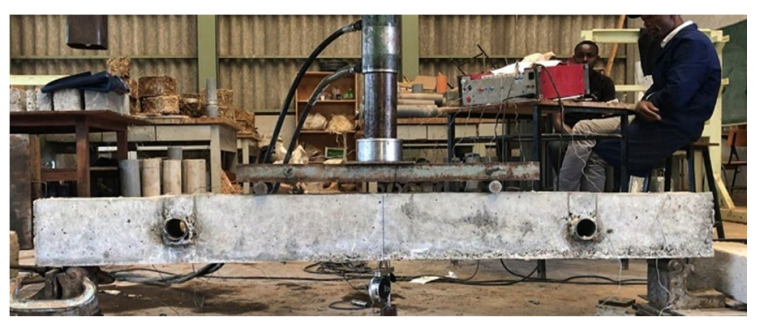

Fig. 4. Test configuration

\section{RESULTS AND DISCUSSION}

Crack pattern and failure mode were observed, and deflections at mid-span were recorded at each increment of loading until failure. The impact of openings on the static behavior of the beams considering the variables of focus was evaluated. The outputs of the tests were compared to those of the control specimen

\section{A. Ultimate Load}

Figure 5 shows a comparison of the ultimate load the control beam could withstand with the maximum load capacity of each group of tested specimen. The control beam, which has no perforations, has utterly failed when the applied load reached $65 \mathrm{kN}$.
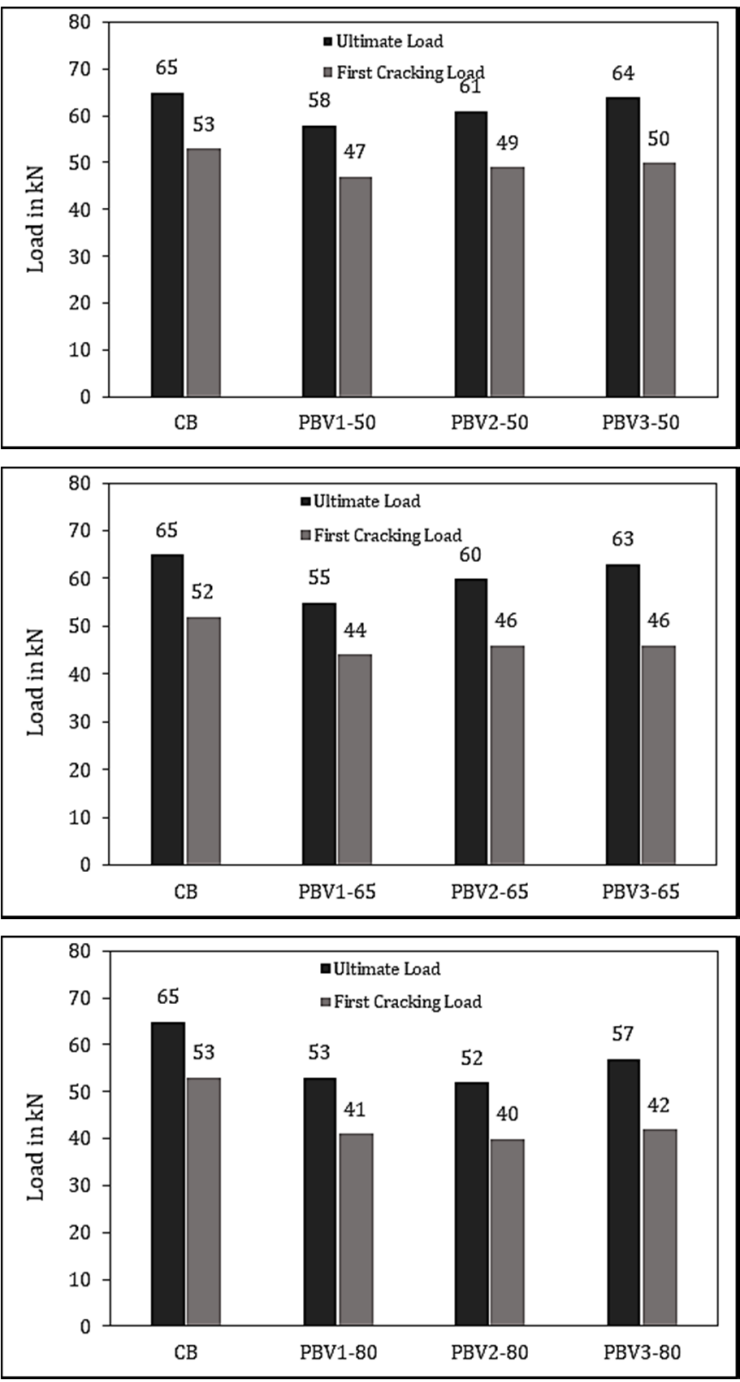

Fig. 5. Ultimate and first cracking soad: (a) set 1, (b) set 2, (c) set 3

The first set of beams with openings sized $0.3 \mathrm{~d}$ (Figure 5(a)) exhibited changes in terms of the ultimate load capacity in function of the position of openings. When transverse holes were inserted above the centroid, the beam failed at $58 \mathrm{kN}$, with a $10.77 \%$ reduction in strength relative to the reference beam. Specimens PBV2-50 and PBV3-50 exhibited higher loadcarrying capacities since the recorded load at collapse was $61 \mathrm{kN}$ and $64 \mathrm{kN}$ respectively. The reduction in strength was small compared to specimen PBV1-50 (6.15\% and $1.54 \%$ respectively. The provision of openings in the upper fibers of the beam (PBV1-50) decreases the contribution of concrete to the overall strength at the opening section. The holes reduce the 
area necessary for the development of a full compressive stress block which made the opening periphery subjected to a strain concentration. Consequently, the collapse occurred at a smaller load compared to the solid beam. In contrast, concrete is not expected to resist tensile stresses, and the existence of an opening in the bottom chords (PBV3-50) did not highly affect the load-carrying mechanism because concrete would have cracked anyway in flexure.

Figure 5(b) and Table $\mathrm{V}$ show that the ultimate load capacity of PBV1-65 and PBV2-65 significantly decreased to $55 \mathrm{kN}$ and $60 \mathrm{kN}$, which were respectively $15.38 \%$ and $7.69 \%$ less than the control's $(65 \mathrm{kN})$. Similarly to PBV1-50, this is caused by the reduction in the area of the compressive stress block caused by the openings. On the other hand, when the openings were located below the mid-depth, PBV3-65 performed a better response with a strength diminution of $3.08 \%$. From Figure 5(c) and Table V, it can be observed that the increase in the size of the openings to $0.5 \mathrm{~d}$ leads to a significant decrease in collapse load by at least $12.31 \%$, as was the case for PBV3-80 while samples PBV1-80 and PBV2-80 recorded a maximum load capacity equivalent to $53 \mathrm{kN}$ and $52 \mathrm{kN}$, which is $18.46 \%$ and $20 \%$ less than the solid beam respectively. In proportion to the depth of the opening, the contribution of concrete to shear resistance is assumed to decrease at the opening region, in addition to the disturbance created in developing the usual bending stress flow resulting in a high reduction in the load-carrying mechanism.

It is concluded that the presence of openings with a diameter less than or equivalent to $40 \%$ of the effective depth of the beam does not result in high reduction in the ultimate load capacity, except in cases where the openings are located above the centroid of the section. On the other hand, openings with a diameter greater than $0.4 \mathrm{~d}$ lead to a reduction of at least $12.31 \%$ in the collapse load. Besides, it is noted that when the openings are located below the centroid, the reduction in strength is not as remarkable as if they are located adjacent to the compression chord.

\section{B. First Cracking Load}

The presence of cracks in a reinforced concrete member usually indicates damage. In reinforced concrete beams, the concrete starts cracking when the tensile stress reaches or exceeds its tensile strength. Authors in [16] distinguishe between active and passive cracks. A crack is said to be active when its width evolves according to the stresses. Then it affects the mechanical properties and the transfer mechanism of the forces within the member. A crack is said to be passive when its width no longer varies appreciably even when it is subjected to various stresses, although this type of cracks usually decreases the deformability of the beams. In this study it was ensured that the concrete tensile properties were kept uniform to all samples, as well as the amount and pattern of reinforcements. Therefore, changes in the cracking behavior were originated from the presence of transverse openings and their positions. The first cracking load of each of the tested specimens can be seen in Figure 5. The control beam experienced the first cracks at a load of $53 \mathrm{kN}$, which is when the beam reached $81.54 \%$ of its ultimate load capacity. The cracks were narrow of a flexural nature at the soffit of the beam. Additionally, it was observed that the width of the corresponding cracks did not change as the load increased.

In the first group of perforated beams with $0.3 \mathrm{~d}$ openings, the cracking behavior remained mostly the same compared to control, as the first cracks propagated in the flexure zone at $48 \mathrm{kN}, 49 \mathrm{kN}$, and $50 \mathrm{kN}$, for PBV1-50, PBV2-50, and PBV3-50 respectively which keeps the first cracking in the range of 78 $81 \%$ of the ultimate load. Figure 6 shows that varying the vertical location induced slight changes. It was noticed that these cracks had an active character as their width kept evolving relatively to loading as well as their propagation which extended to the compressed fibers. This gives an indicator that openings introduced a change in the transfer of the internal forces. Figure 5(b) indicates the cracking load for beams with openings of $0.4 \mathrm{~d}$. The load at the first crack for PBV1-65 did not differ noticeably from that of control, while a change was recorded for PBV2-65 and PBV3-65 (77-73\% of the ultimate load). Figure 6 illustrates that as the openings move toward the tensile chord, the concrete subjected to tension undergoes cracking at an earlier stage. Similarly to the first set, cracks were narrow and vertical located at the soffit of the beam. It can be concluded that having drilled openings in the tension chord decreases the resistance of the beam to tensile stresses although the split-tensile strength of concrete is the same for the three samples. When the diameter of the openings reached $0.5 \mathrm{~d}$, the first cracks appeared at an earlier loading range, specifically at $77.36 \%, 76.92 \%$, and $73.68 \%$ of the ultimate load for PBV1-80, PBV2-80, and PBV3-80 respectively. The cracks were also of a flexural nature at midspan. The width and length of these cracks kept developing until failure, which decreased the deformability of the beam and led to failure at a smaller collapse-load compared to the control beam.

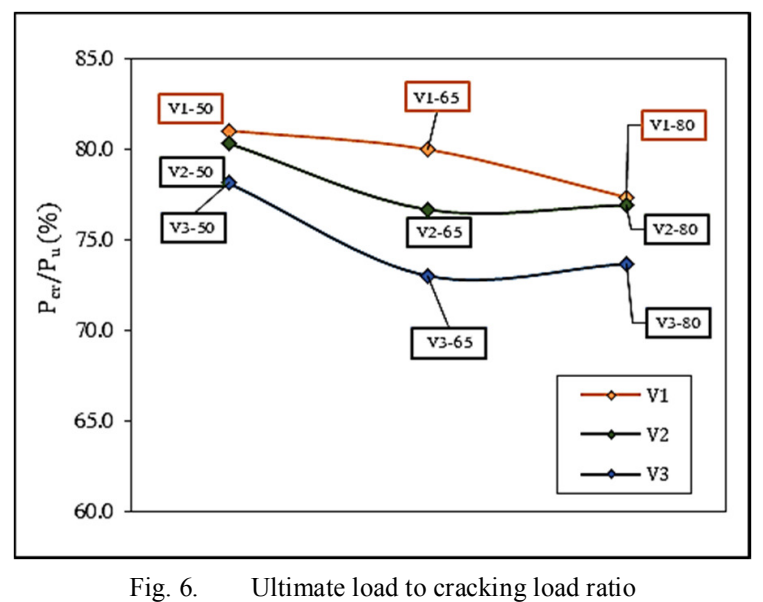

Generally, the propagation of the first crack was found to be affected by the presence of the openings and their vertical position. The conclusions based on the results are:

- The presence of openings at the bottom chords weakens the resistance of concrete to tensile stresses and leads to an earlier cracking. This would disrupt the distribution of 
stresses within the concrete and the stress transfer mechanism from concrete to reinforcements.

- For the same vertical location, circular openings with a diameter equivalent or greater than $0.4 \mathrm{~d}$, lead to an earlier cracking to at least $77 \%$ of the ultimate load.

- Neither the size nor the position of the openings affects the nature of the first crack. It remains a narrow flexural crack at the soffit of the beam.

\section{Load vs Deflection}

Deflection in beams is simply defined as the displacement from its initial position in the direction of the applied load. It is a function of the applied load, the length of span, the flexural rigidity, and the flexural ductility. A high load is necessary to cause a certain deflection at the elastic range to a beam with high flexural rigidity. A beam is said to be ductile when it can perform a large plastic deformation prior to failure or fracture. From the structural safety point of view a good ductility would provide the beam with a much better chance of survival when it is overloaded or subjected to accidental impact. In current codes of practice and in this study, the flexural ductility was controlled by designing the beam as under-reinforced. In this section, the result data of load-deflection curves are discussed from the rigidity and ductility points of view. Table $\mathrm{V}$ indicates the maximum deformation observed on the beams, and Figure 7 compares the load-deflection response of the control beam with other three groups of beams.

TABLE V. ULTIMATE LOAD AND MAXIMUM DEFLECTION

\begin{tabular}{|c|c|c|c|}
\hline Sample & $\begin{array}{c}\text { Ultimate } \\
\text { load (kN) }\end{array}$ & $\begin{array}{c}\text { Difference } \\
\text { percentage (\%) }\end{array}$ & $\begin{array}{c}\text { Deflection at } \\
\text { mid-span }(\mathbf{m m})\end{array}$ \\
\hline CB & 65 & - & 37.00 \\
\hline PBV1-50 & 58 & 10.77 & 27.00 \\
\hline PBV2-50 & 61 & 6.15 & 28.00 \\
\hline PBV3-50 & 64 & 1.54 & 30.00 \\
\hline PBV1-65 & 55 & 15.38 & 20.00 \\
\hline PBV2-65 & 60 & 7.69 & 22.00 \\
\hline PBV3-65 & 63 & 3.08 & 26.00 \\
\hline PBV1-80 & 53 & 18.46 & 15.00 \\
\hline PBV2-80 & 52 & 20.00 & 16.00 \\
\hline PBV3-80 & 57 & 12.31 & 17.00 \\
\hline
\end{tabular}

The CB exhibited a good load-deflection behavior, as its response is composed of the three essential stages before the collapse: elastic, elastoplastic, and plastic stage. When the load increased, the deflection started to increase elastically until the first crack at $52 \mathrm{kN}$, which was followed with a series of flexural cracks, the response shifted to plastic deformation before the complete failure at $65 \mathrm{kN}$. The recorded maximum deflection of the $\mathrm{CB}$ was $37 \mathrm{~mm}$ which can be classified as a ductile failure because the beam deformed plastically. The load-deflection curves for set 1 beams are presented in Figure 7 (a). The perforated beams with a diameter equivalent to $0.3 \mathrm{~d}$ performed a behavior identical to that of the control. The beams had an ability to deform plastically before the collapse, although there was a slight reduction in terms of maximum deflection. Thus, it can be concluded that openings of $0.3 \mathrm{~d}$ size influence neither the rigidity nor the ductility of the beams.
Figure 7(b) illustrates that specimen PBV3-65 kept a response similar to $\mathrm{CB}$, despite that the maximum deflection decreased to $26 \mathrm{~mm}$. In contrast, as the openings move above the mid-depth it was observed that the failure became more brittle as the deformation in the plastic range was small. Moreover, the deflection diminished to $20 \mathrm{~mm}$ and $22 \mathrm{~mm}$ for PBV1-65 and PBV2-65 respectively.

(a)

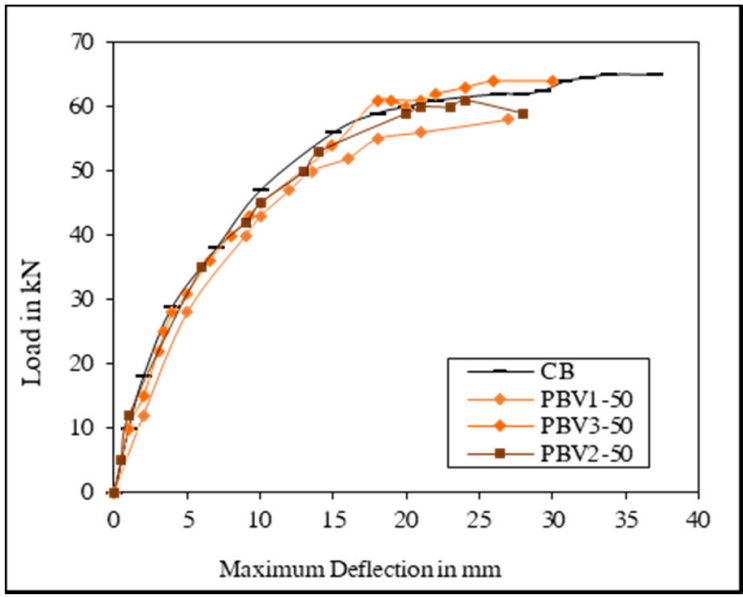

(b)

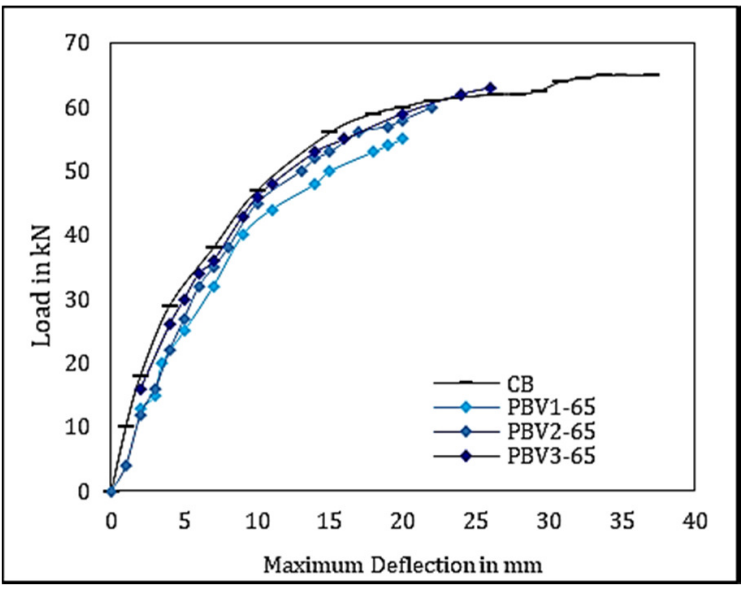

(c)

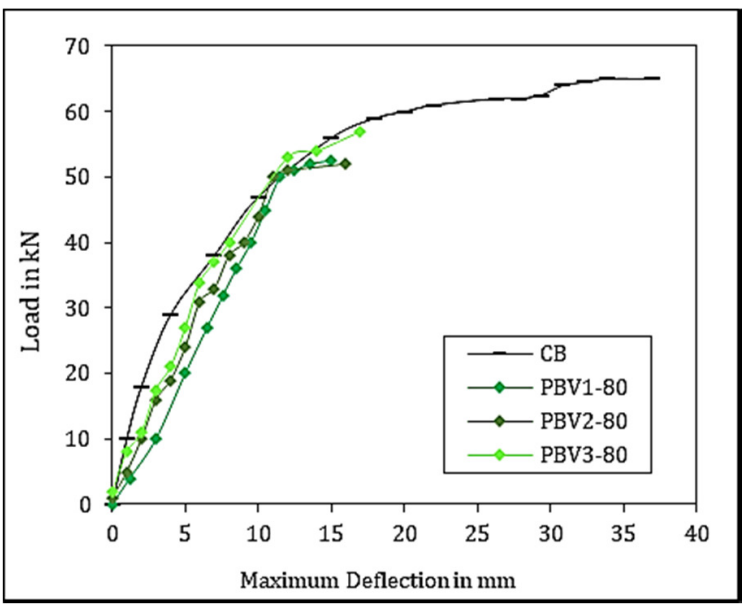

Fig. 7. Load vs. deflection: (a) set 1, (b) set 2, (c) set 3 
From Figure 7(b), it can be seen that the elastic response of specimen PBV3-50 was not influenced by the presence of the openings, only that the plastic deformation decreased recording a maximum deflection of $26 \mathrm{~mm}$. In contrast, PBV1-65 and PBV2-65 deflected more at the elastic range compared to the solid beam under a similar load, which indicates a reduction in the beams' rigidity, hence their stiffness. Moreover, the beams exhibited a brittle failure and a small deformation in the plastic range. The maximum deflections were $20 \mathrm{~mm}$ and $22 \mathrm{~mm}$ for PBV1-65 and PBV2-65 respectively. Similarly, the three beams with openings diameter $0.5 \mathrm{~d}$ had a similar behavior which is characterized by a greater elastic deflection and smaller plastic deformation. The maximum deflections at collapse load were $15 \mathrm{~mm}, 16 \mathrm{~mm}$, and $17 \mathrm{~mm}$ for PBV1-80, PBV2-80, and PBV3-80 respectively. The elastic behavior of the beams is governed by the following matrix:

$$
P=K * u
$$

where $P$ refers to the applied load, $u$ is the induced displacement, and $K$ is the stiffness of the system. The stiffness is a function of rigidity in addition to the length of the member, and the rigidity is a function of material $(E)$ and geometric properties $(I)$. The provision of openings decreases the moment of inertia. Hence, the beams became less stiff and had a larger elastic deflection. On the other hand, the absence/decrease in plastic deflection is related to the effect of openings on the stress-transfer mechanism between concrete and steel. To ensure that a certain level of ductility is achieved, the beams were designed as under-balanced so that steel could be fully stretched. With the openings located adjacent to the compressive chords, concrete in compression was subjected to higher stresses, which caused failure before steel in tension yields.

\section{Crack Pattern and Failure Mode}

Figure 8 shows the crack profile of the beams at the collapse load. When the load was applied to the $\mathrm{CB}$, the deformation began to develop slightly. After the concrete failed in tension, the beam started cracking at a load of $53 \mathrm{KN}$. The first cracks were narrow and vertical at the mid-span. As the beam continued to deflect, flexural fissures kept propagating, until $59 \mathrm{KN}$ where a crack initiated diagonally from the tensile fibers and reached the compression chord which had caused a splitting in the concrete and consequently the beam collapsed. The mode of failure was a diagonal tension-type characterized by ductility and large deflection.

The beams with diameter $0.3 \mathrm{~d}$ openings had different modes of failure compared to control. PBV1-50 and PBV2-50 started to deflect and as the load increased, vertical cracks propagated in the lower end of the segment. The vertical cracks near the openings started to deviate and gather into a $45^{\circ}$ wide diagonal crack which elongated to reach the compressed fibers causing failure. Both samples were found to suffer from excessive cracks, and high damage in the concrete, which may be explained by the influence of the openings on the balance between the tensile and the compressive stress resultants due to the positioning of the openings close to the compression stress block. (a)

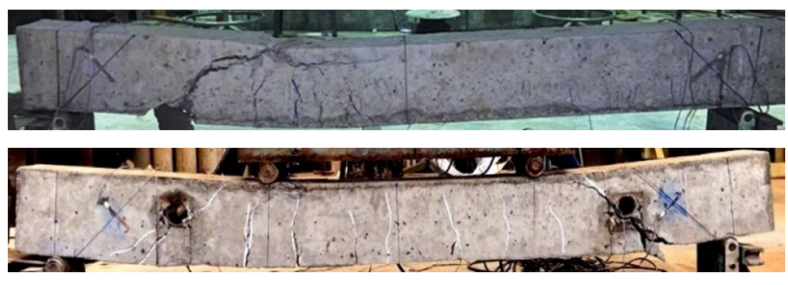

(c)

(d)

(e)

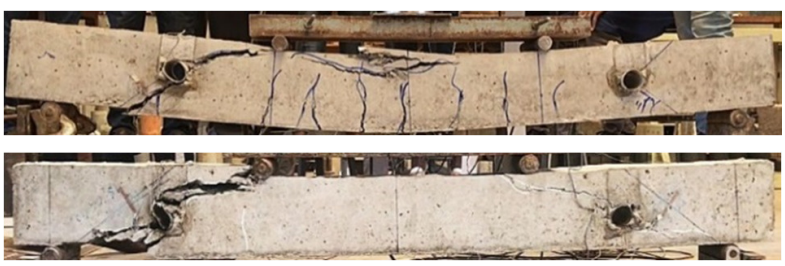

(f)

(g)
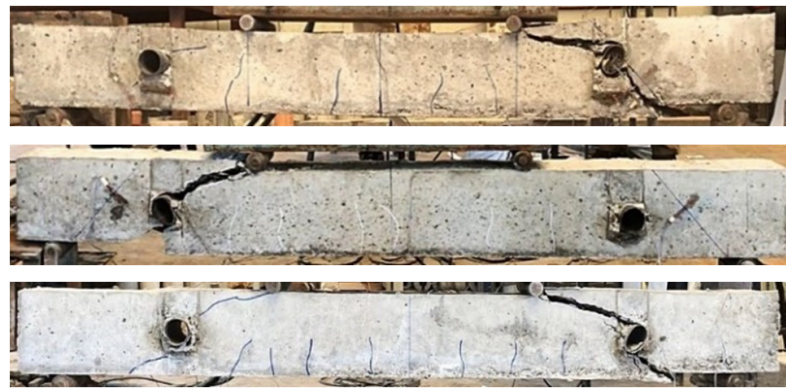

(h)

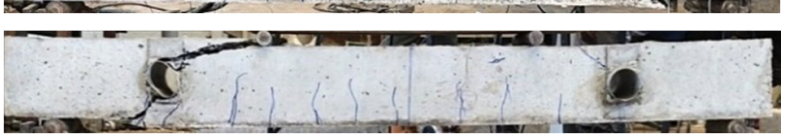

(i)

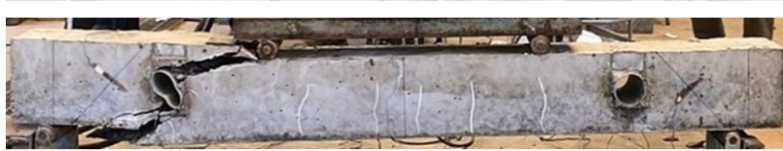

(j)

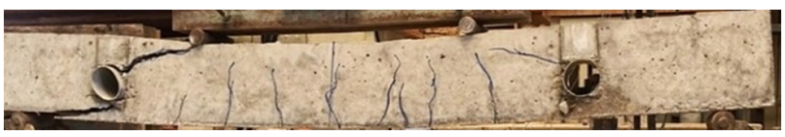

Fig. 8. Crack pattern at failure: (a) CB, (b) PBV1-50, (c) PBV2-50, (d) PBV3-50, (e) PBV1-65, (f) PBV2-65, (g) PBV3-65, (h) PBV1-80, (i) PBV280, (j) $\mathrm{PBV} 3-80$

The response of over-reinforced concrete beams where the assumption that steel yields before concrete is not valid, hence concrete crushes before the steel reaches its yield point, is supported by the data discussed earlier in this paper. PBV3-50 had a more ductile behavior since its plastic deflection was larger than the deflection of the other two samples. As with the $\mathrm{CB}$, the mode of failure is caused by a diagonal tension crack passing through the opening. PBV1-65 had a similar behavior to PBV1-50, except that the deflection was low. The failure mode was a typical diagonal tension failure. In contrast, PBV265 and PBV3-65 suffered cracking at an earlier stage. The cracks were limited in the soffit of the beams until two wide diagonal cracks suddenly appeared below and above the fracture openings. Similarly, the provision of openings with a depth equivalent to $0.5 \mathrm{~d}$ in the third set of samples divided the section into segments. Hence, the collapse was caused by the formation of two independent diagonals below and above the openings. This phenomenon is distinguished for RC beams with large aperture and is denoted as a frame-type failure in reference to the independent behavior of the segments above 
and below the holes which resembles a structural behavior of frames. The cracks that caused the collapse in this group gave no visual warning and were developed suddenly. Hence, the failure was brittle with a small deflection. Moreover, a high local deformation in the opening periphery was observed, caused by the stress concentration in that region.

The applied factored moment $M_{u}$ at the center of the opening from the global action is resisted by the usual bending mechanism, that is by the couple formed by the compressive and tensile stress resultants $N_{u}$ in the members above and below the opening. The presence of the $0.4 \mathrm{~d}$ and $0.5 \mathrm{~d}$ openings created a disequilibrium between the two resultants which caused a rotational effect in the opening region. On the other hand, authors in [1] demonstrated that he applied shear $V_{u}$ is distributed between the two members in proportion to their cross-sectional areas. Thus, they behave independently. Based on the test data, it is evident that the presence of openings affects the crack pattern and the failure mechanism. The beams with opening diameter less than $0.4 \mathrm{~d}$ exhibit a ductile behavior and undergo extensive damage in concrete. The failure is originated from a tension-diagonal crack that passes through the openings. On the other hand, beams with $0.4 \mathrm{~d}$ or greater openings exhibit a brittle behavior. The collapse type is a frame-type failure due to the disequilibrium induced between the stress resultants.

\section{E. Flexure and Shear Capacities}

As discussed above, it is clear that the introduction of openings does not alter the load carrying mechanism as long as the openings are located within the tension zone of the beam because concrete there would have cracked anyway at ultimate flexure. Consequently, the strength of the beam is not affected. This has been confirmed by several researchers in the past such as the authors in [18]. In this section, the equations from [20] were used under the common theories of RC beams subjected to bending and shear.

\section{1) Flexural Strength}

At collapse load, according to the usual flexural strength theory, the applied factored moment $M_{u}$ from the global action is resisted by the usual bending mechanism, that is, by the couple formed by the compressive and tensile stress resultants $N_{u}$. The strain and stress distributions across a section at ultimate are shown in Figure 9.

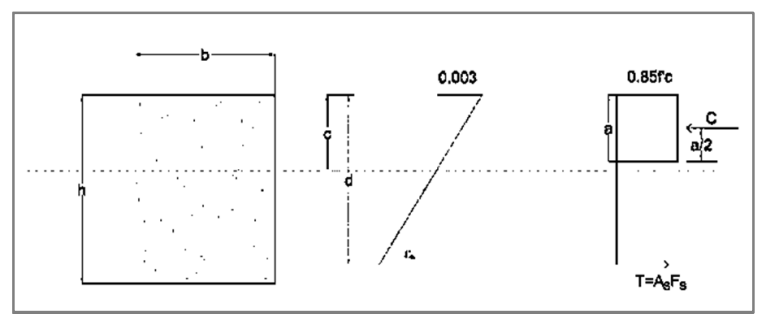

Fig. 9. Conditions at ultimate

Test data showed that if the opening is placed in such a way that it cuts the material from the compression zone, it reduces the concrete area required for the development of the full compressive stress block at ultimate. As a result, $N_{u}$ decreases.
Let us consider specimens $\mathrm{CB}$ and the beams of set 3 . At ultimate, (2) is used to get the compressive stress resultant:

$$
\begin{gathered}
C=0.85 f^{\prime} c \text { ba } \\
C=220.81 \mathrm{kN}
\end{gathered}
$$

The presence of openings in specimens PBV1-80, PBV280, and PBV3-80 reduces the compressive resultant as shown in Figure 10.

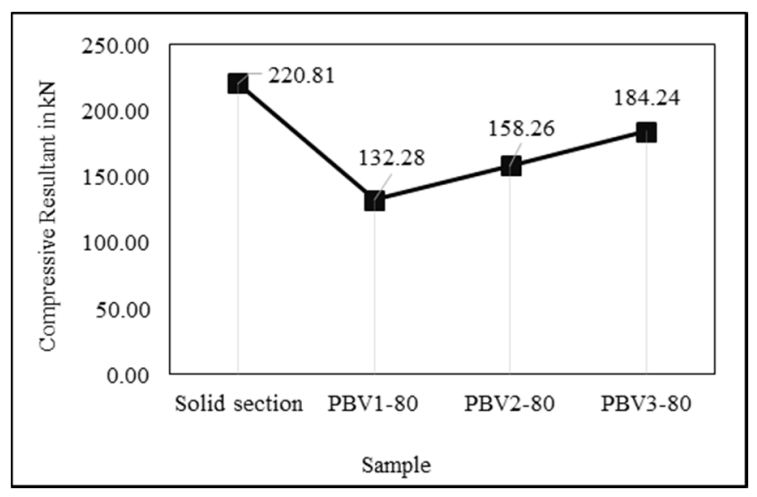

Fig. 10. Compressive resultant for $\mathrm{CB}$ and set 3

It can be observed that having an opening of $0.5 \mathrm{~d}$ size decreased the compressive stress resultant by at least $16 \%$. This reduction is higher when the perforation moves upward toward the compressive surface. The stress resultant $N_{u}$ through the opening section is therefore decreased which led the beams to fail at the same region. Evidently, this explains why the beams of set 3 exhibited much smaller deflection, prior to reaching the full potential capacity.

\section{2) Shear Strength}

Having an opening in the segment leads to a reduction in its depth, affecting the shear resistance in that segment. In this section shear capacities for solid and perforated sections with different diameters are computed and compared. The ACI code [20] design method for shear requires that:

$$
V_{n}>V_{u}
$$

where $V_{n}$ is the nominal shear strength given by combining two components $V_{c}$ and $V_{s}$, and $V_{u}$ is the applied shear force. At the center of the opening $V_{u}=32.5 \mathrm{kN}$. The simplified expression of $V_{c}$ is given by [20]:

$$
V_{c}=\frac{1}{6} \sqrt{ } f_{c}^{\prime} b d
$$

The expression of $V_{s}$ is developed using a $45^{\circ}$ truss model while assuming that shear reinforcements yield at the collapse. The general correlation for $V_{s}$ is given as the sum of vertical and diagonal stirrups $V_{s v}$ and $V_{s d}$. In the current study diagonal stirrups are not involved therefore:

$$
V_{s}=\frac{A_{s v} f_{y v} d_{v}}{\mathrm{~s}}
$$

a) The Control Beam

From (3) the contribution of concrete to the shear strength 
is $V_{c}=20.38 \mathrm{kN}$, while (4) is used to get the shear strength attributed to shear reinforcements around the openings $V_{s}=13.01 \mathrm{kN}$. The nominal shear strength that can be provided by a solid section is therefore $33.39 \mathrm{kN}$. Therefore the condition $V_{n}>V_{u}$ is applied for specimen CB.

\section{b) PBV1-80 Section through the Opening}

In case of a perforated segment, the opening depth is deducted from the simplified expression of $V_{c}$ as follows:

$$
V_{c}=\frac{1}{6} \sqrt{f_{c}^{\prime}} b\left(d-d_{0}\right)
$$

$V_{c}$ becomes $10.38 \mathrm{kN}$, while $V s$ remains the same with the solid section. The reduction in the contribution of concrete to the shear capacity is not affected by the vertical location. Figure 11 shows the nominal shear capacity of the beams through the opening per size. It is observed that with the presence of openings the shear strength of the beam decreases by at least $18.7 \%$. Therefore, the direction of the principal tensile stress changes from horizontal to a direction inclined to the longitudinal axis of the beam through the perforation. Since concrete is weak in tension, this diagonal tensile stress eventually leads to what is basically known as diagonal tension failure of a beam. Adding too much shear reinforcement doesn't seem adequate as failure may also occur by crushing of the concrete in a diagonal direction.

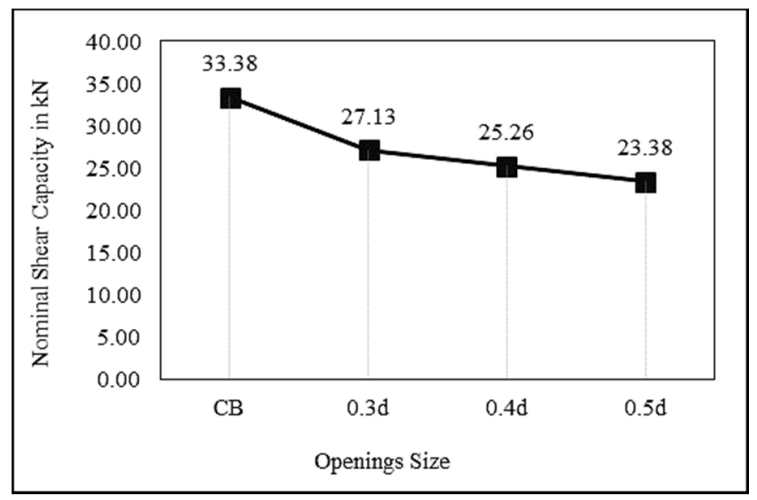

Fig. 11. The nominal shear capacity per opening size

\section{CONCLUSIONS}

The main findings of this study are:

- The provision of openings in the bottom chords with a diameter less than $40 \%$ of the beam's effective depth brings no significant changes in terms of ultimate load capacity or first crack instant.

- Circular openings with a diameter equal or greater than $40 \%$ reduce the beam's strength and lead the beam to premature cracking.

- When openings with a diameter not greater than $0.4 \mathrm{~d}$ are introduced below the centroid, the beam retains both the elastic and the plastic deflections, allowing a certain degree of ductility. In contrast, openings with size more than $0.4 \mathrm{~d}$ make the beam behavior limited at the elastic range with a smaller alarming deflection.
- When the openings are located in compression fibers, the behavior of the beam becomes more brittle with less plastic deformation. Besides, the concrete in the upper fibers undergoes extensive damage and the beam cracks more than usual.

- When the depth of the openings is equal to or greater than $0.4 \mathrm{~d}$, the type of failure changes from a beam-type failure to a frame type that occurs suddenly without significant previous signs. (In case of openings of size $0.4 \mathrm{~d}$, this applies when the location of the openings is not above the centroid).

- Openings located above the mid-depth reduce the area necessary for the formation of the rectangular compressive stress block, which leads to a smaller flexural capacity. Consequently, the beam will exhibit less curvature, hence less deflection.

\section{RECOMMENDATIONS}

Further research work can focus on:

- Investigating the effect of drilling openings in existing reinforced concrete beams.

- Strengthening the periphery of the openings using sisal mat polymer composite.

- Proposing an optimized reinforcement scheme to prevent diagonal tension failure and control the cracks.

- For openings located in the compression chord, replacing PVC pipes which are typically used for inserting circular openings with steel tubes which may have reinforcing actions and more resistance to compressive stresses.

\section{ACKNOWLEDGEMENTS}

The authors will like to thank the African Union Commission, under the flagship program of Pan African University, Institute for Basic Science, Technology and Innovation (PAUSTI) and the AFRICA-ai-JAPAN project for funding this research.

\section{REFERENCES}

[1] M. A. Mansur, "Design of reinforced concrete beams with web openings", Asia-Pacific Structural Engineering and Construction Conference, Kuala Lumpur, Malaysia, September 5-6, 2006

[2] S. Amiri, R. Masoudnia, "Investigation of the oppening effects on the behavior of concrete beams without additional reinforcement in opening region using FEM method", Australian Journal of Basic and Applied Sciences, Vol. 5, No. 5, pp. 617-627, 2011

[3] M. A. Mansur, "Effect of openings on the behaviour and strength of R/C beams in shear", Cement and Concrete Composites, Vol. 20, No. 6, pp. 477-486, 1998

[4] S. A. A. Sheikh, "Flexural behaviour of RC beams with opening", Concrete Research Letters, Vol. 5, No. 2, pp. 812-824, 2014

[5] S. M. Allam, "Strengthening of RC beams with large openings in the shear zone", Alexandria Engineering Journal, Vol. 44, No. 1, pp. 59-78, 2005

[6] S. Amiri, R. Masoudnia, A. A. Pabarja, "The study of the effects of web openings on the concrete beams", Australian Journal of Basic and Applied Sciences, Vol. 5, No. 7, pp. 547-556, 2011 
[7] J. V. Amiri, M. H. Alibygie, "Effect of small circular opening on the shear and flextural behavior and ultimate strength of reinforced concrete beams using normal and high strength concrete", 13th World Conference on Earthquake Engineering, Vancouver, Canada, August 1-6, 2004

[8] W. B. Siao, S. F. Yap, "Ultimate behavior of unstrengthen large openings made in existing concrete beams", Journal of the Institution of Engineers, Vol. 30, No. 3, pp. 51-57, 1990

[9] British Standards, BS 882 (1992): Specification for aggregates from natural sources for concrete, British Standards, 1992

[10] European Standard, EN 197-1 (2000): Cement-part 1: Composition, specifications and conformity criteria for common cements, European Standard, 2000

[11] ASTM A1096/A1096M-15 (2015): Standard test method for evaluating bond of individual steel wire, indented or plain, for concrete reinforcement, ASTM A1096/A1096M-15, 2015

[12] D. C. Teychenne, R. E. Franklin H. C. Erntroy, Design of normal concrete mixes, Bre Press, 1997

[13] K. Hover, "Testing hardened concrete", Publication \#C930727, The Aberdeen Group, 1993

[14] R. S. Narayanan, K. R. Wilson, R. J. W. Milne, Manual for the design of reinforced concrete building structures to EC2, The Institution of Structural Engineers, 2000

[15] G. N. J. Kani, "The riddle of shear failure and its solution”, ACI Journal Proceedings, Vol. 61, No. 4, pp. 441-468, 1964

[16] Association Francaise de Normalisation, Structure-repair and strengthening of concrete engineering structures-treatment of cracks and protection of concrete-specifications for the technique and materials used, Association Francaise de Normalisation, 2014

[17] R. C. Murthy, G. S. Palani, N. R. Iyer, "Residual strength evaluation of unstiffened and stiffened panels under fatigue loading", Structural Durability \& Health Monitoring, Vol. 5, No. 3, pp. 201-226, 2009

[18] H. A. Abdalla, A. M. Torkey, H. A. Haggag, A. F. A. Amira, "Design against cracking at openings in reinforced concrete beams strengthened with composite sheets", Composite Structures, Vol. 60, No. 2, pp. 197204, 2003

[19] T. Ozbakkaloglu, M. Saatcioglu, "Rectangular stress block for highstrength concrete", Aci Structural Journal, Vol. 101, No. 4, pp. 475-483, 2004

[20] American Concrete Institute, ACI 318-95 (1995): Building Code Requirements for Structural Concrete and Commentary, American Concrete Institute, 1995 